J. Clin. Chem. Clin. Biochem.

Vol. 27, 1989, pp. $365-368$

(C) 1989 Walter de Gruyter \& Co. Berlin · New York

\title{
Automated Blood Count Analysis by Trimodal Size Distribution of Leukocytes with the SYSMEX E-5000
}

\author{
By W. Bürgi and H.R. Marti \\ Zentrallaboratorium, Kantonsspital, Aarau, Schweiz
}

(Received January 20/April 6, 1989)

\begin{abstract}
Summary: The automated haematology analyser, SYSMEX E-5000, measures and computes quantitative haematological parameters, and determines the size distribution of blood cells and platelets. After partial lysis, the analyser classifies the leukocytes into 3 populations:

small cells (lymphocytes), intermediate sized cells (basophils, eosinophils, monocytes) and large cells (neutrophils, including band cells).

One thousand blood samples from inpatients and outpatients were analysed automatically in the SYSMEX as well as being submitted to microscopic blood smear differentiation, and the results were compared. The trimodal size distribution of the automated analysis revealed $1.8 \%$ false normal results. Ten cases of eosinophilia of between 6.6 and $12.5 \%$ remained undetected by the automated method, which also failed to detect 7 cases of left shift with normal leukocyte count, as well as a single sample containing $2 \%$ of myelocytes. Both diagnostic sensitivity and diagnostic specificity were high, i.e. $97.1 \%$ and $81.8 \%$, respectively. The predictive values were also high for both pathological and normal results. Since certain changes in blood cell morphology are not detected by the SYSMEX, certain clinical indications still call for a microscopic blood smear examination. With due regard to these limitations, the apparatus yields reliable results and economizes considerably the routine laboratory work load. In the present study, $31 \%$ of the microscopic blood cell differential counts were saved by using the SYSMEX E-5000.
\end{abstract}

\section{Introduction}

The need to economize on manual procedures in the haematology laboratory is undisputed. Analysers have been developed for the automation of timeconsuming microscopic blọod cell differentiation (1, 2). These analysers classify leukocytes according to their cytochemical behaviour $(3,4,5)$, or according to conventional morphological criteria, using an optical-electronic system (5). A third group of automated analysers performs a partial differentiation of leukocytes in cell populations. The SYSMEX E-5000 Analyser (Toa Medical Electronics Co., Ltd.) quantifies cell numbers, calculates the indices, and, after partial cell lysis, classifies the leukocytes into 3 populations according to size: small cells (lymphocytes), intermediate size cells (basophils, eosinophils, monocytes), and

large cells (neutrophils, including band cells) $(6,7)$.

These three cell populations and the size distribution of the erythrocytes and thrombocytes, respectively, are recorded graphically. Studies on the diagnostic value of the size distribution of erythrocytes in thalassaemia screening were reported recently (8). A recent communication compared the reliability of results from the SYSMEX E-4000 with those from the Technicon H6000 (9). In the present work, the trimodal leukocyte size distribution determined by the SYSMEX E-5000 is compared with the results of microscopic blood cell differentiation. 


\section{Materials and Methods}

SYSMEX E-5000

This analyscr determines 18 haematological parameters, including the trimodal size distribution of leukocytes and the size distribution of erythrocytes and thrombocytes respectively. The quantitative values are expressed numerically, and the distribution diagrams are generated graphically. Details of the operation and performance of the apparatus are available from the manufacturer (supplier: Digitana $\mathrm{AG}, \mathrm{CH}-8810$ Horgen, $\mathrm{ZH})$.

\section{Blood samples}

Venous blood was taken from a total of 1000 inpatients and outpatients, using vacutainers with potassium-EDTA as anticoagulant. Each sample was analysed manually by microscopic differentiation of the blood smear, as well as in the haematological analyser SYSMEX E-5000. Since the analytical reliability of the apparatus is proven $(6,9,10,11)$, the numerical parameters were not examined.

\section{Evaluation criteria}

Each microscopic analysis was performed on 200 cells. Results were classified as "normal" if the numerical haematological parameters from the automated analysis and from the microscopic investigation both laid in the normal range. They were classified as "pathological" if the quantitative parameters determined in the SYSMEX E-5000 and/or the microscopic results laid outside the normal limits. Accordingly, the results from the analyser were classified as "normal" (total SYSMEX results in the normal range) or "pathological" (quantitative haematology and/or size distribution diagrams outside the normal range). Assignment of the classification "normal" or "pathological" was based on accepted laboratory values for microscopic blood cell differentiation, and on the reference ranges provided by the apparatus manufacturer for cell numbers and cell populations (tab. 1). Each sample analyzed was placed in one of four groups: "true normal" (TN), "true pathological" (TP), "false normal" (FN), and "false pathological" (FP) (tab. 2). The following indices were calculated (11):

diagnostic sensitivity $=\mathrm{TP} /(\mathrm{TP}+\mathrm{FN})$;

diagnostic specificity $=\mathrm{TN} /(\mathrm{TN}+\mathrm{FN})$;

predictive value of the pathological SYSMEX result $=T P /$ $(\mathrm{TP}+\mathrm{FP})$

predictive value of the normal SYSMEX result $=\mathrm{TN} /$ $(\mathrm{TN}+\mathrm{FN})$.

Tab. 1. Normal ranges for microscopic blood cell differentiation and for the SYSMEX E-5000 leukocyte populations. Based on these ranges, the results are classified as "normal" or "pathological".

\begin{tabular}{lrlr}
$\begin{array}{l}\text { Microscopic differentiation } \\
(\%)\end{array}$ & $\begin{array}{l}\text { SYSMEX E-5000 populations } \\
(\%)\end{array}$ \\
\hline Band nuclei & $0-10$ & Large cells & $50-75$ \\
Segmented nuclei & $40-75$ & & \\
Basophils & $0-1$ & & \\
Eosinophils & $0-6$ & Medium sized cells & $2-15$ \\
Monocytes & $2-10$ & & \\
Lymphocytes & $20-40$ & Small cells & $20-40$ \\
\hline
\end{tabular}

\section{Results}

Microscopic differentiation of the blood smears from all patients revealed 379 (37.9\%) "normal" and 621 $(62.1 \%)$ "pathological" results. Of the microscopic "normals", the SYSMEX E-5000 recognized 310 $(82 \%)$ als "normal", and classified the remaining 69 $(18 \%)$ as "pathological". Based on the total of 1000 samples, the SYSMEX E-5000 produced $6.9 \%$ "false pathological" results. Out of the 621 pathological microscopic results, the SYSMEX E-5000 classified $18(2.9 \%)$ as normal, i. e. $1.8 \%$ of the total samples. The reliability with which a single SYSMEX result can be considered as "true normal" or "true pathological" is shown in table 2 . Results classified as "false normal" include ten cases of eosinophilia between 6.5 and $12.5 \%$, seven cases of left shift with non-elevated total leukocyte count, and a sample containing $2 \%$ myelocytes. The diagnostic sensitivity, diagnostic specificity, and the predictive values of the SYSMEX results are shown in table 3.

Tab. 2. Evaluation of the analysis of 1000 blood samples by the SYSMEX. Microscopic "normal" means that blood cell counts in the SYSMEX and the microscopic results are both in the normal range. Microscopic "pathological" applies to samples for which cell counts by the analyser and/or the microscopic results are outside the normal values. A "normal" SYSMEX result means that all the values, including the distribution diagrams, are in the normal range. A SYSMEX result is designated "pathological" if the cell count and/or the distribution pattern is outside normal limits.

\begin{tabular}{|c|c|c|c|c|}
\hline \multicolumn{2}{|c|}{ Classification of results } & \multicolumn{3}{|c|}{$\begin{array}{l}\text { Evaluation of the } \\
\text { SYSMEX results }\end{array}$} \\
\hline Microscopic & $\begin{array}{l}\text { SYSMEX } \\
\text { E-5000 }\end{array}$ & Group̄s & $\mathrm{N}$ & $\%$ \\
\hline normal & normal & $\begin{array}{l}\text { true } \\
\text { normal }\end{array}$ & 310 & 31.0 \\
\hline pathological & pathological & $\begin{array}{l}\text { true } \\
\text { pathological }\end{array}$ & 603 & 60.3 \\
\hline pathological & normal & $\begin{array}{l}\text { false } \\
\text { normal }\end{array}$ & 18 & 1.8 \\
\hline normal & pathological & $\begin{array}{l}\text { false } \\
\text { pathological }\end{array}$ & 69 & $6: 9$ \\
\hline
\end{tabular}

Tab. 3. Diagnostic values of the SYSMEX E-5000 results, expressed as the $\%$ probability compared with the results of the microscopic differentiation of the blood smear.

\begin{tabular}{lc}
\hline Diagnostic sensitivity & 97.1 \\
Diagnostic specificity & 81.8 \\
Predictive value of the: &, \\
$\quad$ normal result & 89.7 \\
pathological result & 94.5 \\
\hline
\end{tabular}




\section{Discussion}

The results of this study show that the SYSMEX produces only a small proportion of "false normal" results, representing $1.8 \%$ of the total. Most of these false classifications are represented by cases of mild eosinophilia with no accompanying increase in the population of medium-sized leukocytes, and by left shifts without increased leukocyte count, i.e. abnormal findings that are unrecognizable by the instrument. It is necessary for the operator to be aware of the limitations of the equipment: it does not differentiate between neutrophils with banded and segmented nuclei; it cannot distinguish between erythroblasts and leukocytes; it is generally insensitive to abnormal cells that are present in only small numbers; and it does not recognize intracellular parasites. The clinician must appreciate the limitations of the apparatus, in order to decide whether a microscopic blood smear analysis is necessary. Conditions that primarily call for microscopic blood smear examination are summarized in table 4. Abnormal results from the SYSMEX should also be followed by microscopic blood smear examination.

Tab. 4. Indications for the microscopic blood smear examination

At the request of the clinician

Undefined anaemia

Leukaemia

Metastasing malignancy

Acute infection

Leukopenia

Eosinophilia

\section{Instigated by the laboratory}

Pathological SYSMEX E-5000 result

The calculated diagnostic sensitivity and predictive value are satisfactory. The somewhat low diagnostic specificity of $81.8 \%$ and the predictive value of a pathological result of $89.7 \%$ are essentially due to the $6.9 \%$ of "false pathological" SYSMEX results. This merely means that the samples in question must be differentiated by microscopic examination, which is no disadvantage to the clinician. The diagnostic sensitivity of $97.1 \%$ is decidedly high, i.e. there is $97.1 \%$ probability that a pathological condition detected by microscopic examination will also be recorded as pathological by the SYSMEX. At $94.5 \%$, the predictive value of the normal SYSMEX result is also high. This represents the probability that a blood sample recorded as normal by the SYSMEX will also be evaluated as normal in microscopic examination.

It can be concluded from the present study that while certain clinical conditions may a priori call for a microscopic blood smear examination, this time-consuming and labour intensive manual procedure can otherwise be omitted from routine haematological analysis. This permits a more economic organization of the haematological laboratory. In the present study, microscopic blood smear differentiation was unnecessary for 310 out of 1000 samples, i.e. $31 \%$ of the workload, representing a saving of $80-100$ man hours by using the SYSMEX. This saving is especially important for the stand-by and emergency services, which are less well staffed.

Many haematological laboratories reduce their workload, whenever possible, by determining only the haemoglobin concentration and the leukocyte count. Compared with this practice, the SYSMEX presents considerably more useful information, such as the proportion of neutrophils and lymphocytes in the leukocyte population, the erythrocyte count, haematocrit, erythrocyte indices, degree of erythrocyte anisocytosis, as well as the platelet count. All these parameters are determined at no extra cost in time or personel. Whenever modern analysers are introduced into the haematological laboratory, a special effort must be made to instruct the clinician as to the informational content of the results produced by these automated machines. This aim is best achieved by promoting a dialogue between the laboratory director and the clinician.

\section{References}

1. Neumann, E. (1983) Automation im hämatologischen Laboratorium, In: Laboratoriumsdiagnose 1. Hämatologie und Immunhämatologie. (Huber, H., Pastner, D. \& Gabl, F., eds.) pp. $469-486$, Springer=Verlag, Berlin.

2. Lifshitz, M. S. \& de Cresce, R. P. (1986) Understanding, Selecting and Acquiring Clinical Laboratory Analyzers. pp. 95-121, Alan R. Liss, Inc., New York, USA.

3. Schneider, W. (1985) Ein notfalltaugliches Tischsystem für das kleine und große Blutbild, GIT Labor-Medizin 8, 428433.

4. Schneider, W. (1986) Ein flexibler Hämatologie-Analysator mit neuartigen Meßtechniken und diagnostischen Aussagen. mta $1,301-310$.

5. Wielders, J. P. M., Beunis, M. H. \& Van Wersch, J. W. J. (1986) A Comparison of the Screening Ability of two Automated Leukocyte Differential Counters. J. Clin. Chem. Clin. Biochem. 24, 471-480.

6. Tatsumi, N., Tsuda, I., Fujimoto, K. \& Matsumoto, H. (1985) Evaluation of a New Blood Cell Counter With Sheath Flow System. Cytometry 6, 395-400. 


\section{Thermodynamics and \\ Pattern Formation in Biology}

Editors I. Lamprecht $\cdot$ A. I. Zotin

1988. $17 \mathrm{~cm} \times 24 \mathrm{~cm}$. XIII, 518 pages. Numerous illustrations.

Hardcover DM 398,-; approx. US \$241.00 ISBN 3110113686

This fourth monograph in a series concerning "Thermodynamics and Biological Processes" deals with questions connected with the emergence of temporal and spatial structures in living units and traces such pattern formation back to inanimate systems.

Emergence of order in living and inanimate systems is one of the most fascinating and thrilling topics in modern natural sciences.

This book will be useful for all those biochemists, biophysicists, physiologists and developmental biologists dedicated to the appearance of pattern in living systems, but moreover to theoretical physicists and mathematicians interested in recent questions of biological thermodynamics and mathematics.

From the Contents

General Problems - Pattern Formation in Chemical and Biochemical Systems . Pattern Formation in Biological Systems - List of Contributors - References · Subject Index

Also available

\section{Thermodynamics of Biological Processes}

Editors I. Lamprecht $\cdot$ A. I. Zotin

1978. DM 200,-; approx. US $\$ 115.00$

\section{Thermodynamics and Kinetics of Biological Processes}

Editors I. Lamprecht $\cdot$ A. I. Zotin

1982. DM 270,-; approx. US $\$ 155.00$

\section{Thermodynamics and Regulation of Biological Processes}

Editors I. Lamprecht $\cdot$ A.I. Zotin

1985. DM 270,-; approx: US $\$ 155.00$

Prices are subject to change without notice 


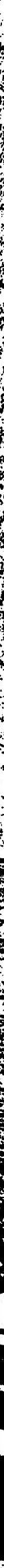


7. Thom, R. (1987) Neue Gerätetechnologie und Parameter in der Hämatologie. In: Trends in der Hämatologie (Hohenwallner, H., ed.) pp. 81-97, TOA MEDICAL ELEÇTRONICS Deutschland GmbH, Hamburg.

8. Marti, H. R., Fischer, S., Killer, D. \& Bürgi, W. (1987) Can Automated Haematology Analysers Discriminate Thalassaemia from Iron Deficiency? Acta Haematol. 78, $180-183$.

9. Pohland, D. (1989) Evaluation of the Automated Haematology Analyser Sysmex M-2000. J. Clin. Chem. Clin. Biochem. 27, $41-47$.
10. Smeets, E. H. J. \& van Wersch, J. W. J. (1988) Performance of a Three-Part Dif Impedance Cytometer (SYSMEX E4000) in Comparison with a Cytochemical Cytometer (Technicon H 6000). J. Clin. Chem. Clin. Biochem. 26, $531-540$.

11. Vavra, Z. \& Bernard, J. C. (1987) Die kontinuierliche Qualitätssicherung der industriellen Herstellung vơn Köntrollblut. In: Trends in der Hämatologie (Hohenwallner, W., ed.) pp. 31-40, TOA MEDIÇAL ELECTRONICS Deutschland GmbH, Hamburg.

12. Keller, H. (1986) Klinisch-chemische Labordiagnostik für die Praxis, pp. 155-157, Georg Thieme Verlag, Stuttgart.

Prof. Dr. W. Bürgi

Zentrallaboratorium

Kantonsspital

CH-5001 Aarau 


\section{Concise Encyclopedia Biochemistry}

\section{Second Edition,}

revised and expanded by Thomas Scott and Mary Eagleson

1988. $17 \mathrm{~cm} \times 24 \mathrm{~cm}$. 650 pages. Hardcover. DM 148,-; approx. US $\$ 89.00$

ISBN 3110116251

The only single work of its kind in English, the Concise Encyclopedia of Biochemistry provides a comprehensive, yet compact, source of biochemical data and information for the researcher, teacher, and student.

Following a five-year program of collecting and editing new material, as well as the revision of existing entries, the author-editors and the publishers are pleased to announce the new expanded Second Edition of this valuable reference work.

Major entries concerning the latest developments in DNA structure, synthesis, sequencing, binding proteins and methods, oncogenes, lymphokines and other newly discovered regulatory peptides, structural proteins, inositol phosphates, and protein kinases have been added. Graphic illustration has been given high priority, so that regulatory processes, transport, subcellular structures, etc. are abundantly and clearly illustrated.

The coverage of plant biochemistry has also been greatly expanded. Another new addition is a section on buffers which will be useful to anyone involved in laboratory work. Because of its comprehensiveness and multidisciplinary nature, we are sure that you will find it an indispensable reference tool.

Special features of this edition include:

- Approximately 4,500 entries

- Up-to-date, comprehensive

- Coverage of medical, animal, microbial, plant, and physical biochemistry, natural products, molecular biology, molecular genetics, and biotechnology

- Hundreds of illustrations, including structural formulas, schemes, and metabolic pathways

O Over 100 tables

- Modern terminology based on standard sources, e. g., IUB Enzyme Nomenclature

- Standard biochemical abbreviations

- Extensive cross references with synonyms provided

- Literature references are cited to aid the reader in locating original sources

Potential audience: biochemists, clinical biochemists, clinical chemists, medical researchers, clinicians, plant scientists, experimental biologists, lecturers and students of the life sciences. 